\title{
MENINGKATKAN PENGETAHUAN IBU MENYUSUI MENGENAI PEMBERIAN MAKANAN PENDAMPING ASI (MP-ASI) MELALUI PENYULUHAN KESEHATAN DI PBM CITRA LESTARI BOGOR
}

\author{
Kasyafiya Jayanti ${ }^{1}$, Sri Hayuningsih ${ }^{2}$, Estu Lovita Pembayun ${ }^{3}$, Gracea Petricka ${ }^{4}$ Sisilia \\ Prima $^{5}$, Rochmawati ${ }^{6}$, Arini Kusmintarti ${ }^{7}$, Veronica Fary ${ }^{8}$, Liana Elfaristo ${ }^{9}$ \\ Kebidanan, Fakultas Farmasi dan Ilmu Kesehatan, Universitas Gunadarma \\ Jl. Raya Bogor KM.31 N0.28-30 Cisalak Pasar, Depok, Jawa Barat-16452 \\ kasyafiyajayanti@staff.gunadarma.ac.id ${ }^{1}$, srihayuningsih@staff.gunadarma.ac.id ${ }^{2}$, \\ estulovita@staff.gunadarma.ac.id ${ }^{3}$, gracepetricka@staff.gunadarma.ac.id ${ }^{4}$, \\ sisilia.prima@staff.gunadarma.ac.id ${ }^{5}, \underline{\text { ramadhan.rochmawati@staff.gunadarma.ac.id }}^{6}$, \\ arini@staff.gunadarma.ac.id ${ }^{7}$, varry@staff.gunadarma.ac.id ${ }^{8}$, \\ liana_elfaristo@staff.gunadarma.ac.id ${ }^{9}$
}

\begin{abstract}
ABSTRAK
Makanan Pendamping ASI (MP-ASI) diberikan pada bayi berusia 6-24 bulan untuk memenuhi kebutuhan gizi selain ASI yang telah didapatkan sebelumnya. Namun, pada kenyataannya masih banyak ibu menyusui yang tidak mengetahui tentang pemberian MP-ASI yang tepat. Berdasarkan hasil kuesioner yang diikuti 20 orang ibu menyusui di Praktik Bidan Bersama Citra Lestari didapatkan bahwa seluruh responden memiliki tingkat pengetahuan yang rendah terkait ketepatan pemberian MP-ASI (rerata skor pretest 36). Oleh karena itu Program Studi Kebidanan Universitas Gunadarma melakukan pengabdian masyarakat yang bertujuan meningkatkan pengetahuan ibu menyusui tentang ketepatan waktu, frekuensi, jenis bahan makanan, jumlah dan cara pengolahan serta pemberian MP-ASI. Pengabdian masyarakat ini berupa penyuluhan kesehatan yang dilakukan secara daring melalui media Zoom meeting bekerjasama dengan Praktik Bidan Bersama Citra Lestari. Terjadi peningkatan pengetahuan responden sebesar 1,2 kali lipat yang ditandai dengan meningkatnya rerata skor posttest menjadi 80 .
\end{abstract}

Kata Kunci: MP-ASI, gizi, ibu menyusui

\begin{abstract}
Weaning food are given to babies aged 6-24 months to meet their nutritional needs and complement breast milk. However, there are still many breastfeeding mothers who do not know to give a proper weaning food. A questionnaire followed by 20 breastfeeding mothers at the Citra Lestari Joint Midwife Practice shows that all respondents had a low level of knowledge about proper weaning food (mean pretest score was 36). Therefore, Gunadarma University Midwifery Study Program perform a community service to enhance the knowledge of breastfeeding mothers about the timeliness, frequency, types of foodstuffs, the amount and method of processing, and giving weaning foods. This community service is given as online health education via Zoom in collaboration with the Citra Lestari Joint Midwife Practice. Results shows an enhancement in respondents' knowledge were indicated by an increase of 1.2 times the average posttest score to 80 .
\end{abstract}

Keywords: weaning food, nutrition, breastfeeding mothers

\section{PENDAHULUAN}

World Health Organization merekomendasikan dalam Global Strategy for Infant and Young Child untuk mencapai tumbuh kembang optimal, maka hal yang harus dilakukan 
pertama adalah memberikan ASI (Air Susu Ibu) kepada bayi 30 menit setelah kelahiran, kedua memberikan ASI eksklusif sampai bayi berusia 6 bulan, ketiga memberikan Makanan Pendamping ASI sejak bayi berusia 6-24 bulan dan keempat terus memberikan ASI sampai 24 bulan.

ASI merupakan makanan terbaik bagi bayi. ASI mengandung immunoglobulin yang dapat memberi imunitas pada bayi yang berasal dari ibu. Seiring pertumbuhan bayi maka kebutuhan bayi akan gizi pun semakin meningkat. Pemberian makanan tambahan di butuhkan saat bayi berusia lebih dari 6 bulan. Makanan Pendamping ASI (MP-ASI) diberikan pada saat bayi berusia 6-24 bulan bersamaan dengan ASI, guna memenuhi kebutuhan gizi selain dari ASI. Kebutuhan bayi akan energi dan nutrisi mulai melebihi apa yang disediakan oleh ASI pada usia 6 bulan dan makanan pendamping diperlukan untuk memenuhi kebutuhan tersebut. Namun pada praktiknya, makanan pendamping sering memiliki kualitas gizi yang tidak memadai, atau diberikan secara tidak tepat sehingga menyebabkan pertumbuhan bayi dapat terhambat.

Dalam pemberian MP-ASI terdapat banyak hal yang perlu diperhatikan agar gizi yang didapatkan anak bisa optimal. Hal-hal yang perlu diperhatikan dalam pemberian MP-ASI antara lain waktu pemberian, frekuensi, jenis bahan makanan, jumlah dan cara pengolahan. Pemberian MP-ASI terlalu dini dapat menurunkan tingkat konsumsi ASI, karena sudah ditambahakan MP-ASI. Demikian dengan pemberian MP-ASI yang terlambat dapat menyebabkan bayi sulit menerima MP-ASI. Ibu merupakan salah satu faktor pendukung keberhasilan dalam pemberian MP-ASI. Ibu diharapkan dapat memahami dan mempraktekan cara memberi MP-ASI dengan tepat agar kebutuhan dan kecukupan gizi bayi dapat terpenuhi dengan baik.

Selama masa pemberian MP-ASI, anak beresiko mengalami gizi kurang. Kualitas gizi makanan yang diberikan seringkali tidak memadai, atau diberikan terlalu dini atau terlambat, pemberian dalam jumlah terlalu sedikit atau tidak cukup sering. Penelitian yang dilakukan oleh Park (2012), menunjukkan bahwa pemilihan makanan yang tidak tepat dikaitkan dengan tingginya prevalensi malnutrisi pada anak dibawah usia lima tahun. Terdapat banyak faktor yang berhubungan dengan pemberian MP-ASI dini oleh ibu. Fkctor tersebut antara lain tingkat pengetahuan ibu, status pekerjaan, iklan MP-ASI, petugas tenaga kesehatan, sosial budaya dan ekonomi. Salah satu yang erat dalam kaitannya pemberian MP-ASI adalah pengetahuan ibu. Pengetahuan ibu yang masih kurang dapat menjadi pemicu pemberian MP- 
ASI dini. Faktor penghambat kelanjutan pemberian ASI adalah pengetahuan dan keyakinan ibu bahwa tingkat gizi masih kurang apabila hanya diberikan ASI saja sampai 6 bulan.

Berdasarkan hasil survei di masyarakat yang dilakukan di wilayah Kabupaten Bogor, didapatkan masih banyak ibu menyusui yang tidak mengetahui mengenai pemberian MP-ASI dengan tepat. Kegiatan penelitian dan pengabdian masyarakat ini dilakukan di wilayah kerja Praktik Bidan Mandiri Citra Lestari Kabupaten Bogor. Pengambilan data awal dilakukan dengan melakukan wawancara terhadap ibu menyusui. Hasil wawancara didapatkan ibu memiliki tingkat pengetahuan yang rendah terhadap ketepatan dalam pemberian MP-ASI. Pemberian MP-ASI tidak akan optimal apabila tidak diberikan secara tepat. Oleh sebab itu ibu menyusui harus memiliki pengetahuan yang baik dalam pemberian MP-ASI agar dapat memberikan MP-ASI dengan tepat kepada bayinya.

Permasalahan yang utama yang dihadapi oleh Mitra adalah kurangnya pengetahuan ibu dalam ketepatan pemberian makanan pendamping ASI (MP-ASI). Berdasarkan analisis permasalahan tersebut, Program Studi Kebidanan Universitas Gunadarma, melalui program pengabdian kepada masyarakat bermaksud memberikan kontribusi sesuai dengan bidang keilmuan yang dimiliki yakni dengan memberikan pendidikan kesehatan berupa penyuluhan mengenai ketepatan Pemberian Makanan Pendamping ASI (MP-ASI) bekerjasama dengan Praktik Bidan Bersama Citra Lestari, Kabupaten Bogor.

Berdasarkan hasil pengkajian terdapat 20 orang ibu menyusui yang menjalani persalinan di Praktik Bidan Bersama Citra Lestari. Sebanyak 20 orang ibu menyusui diberikan kuesioner pretest mengenai ketepatan dalam pemberian MP-ASI. Kuesioner diberikan secara daring melalui google form. Bekerjasama dengan Praktik Bidan Mandiri Citra Lestari. Kuesioner diberikan untuk mengetahui sejauh mana pengetahuan ibu mengenai ketepatan dalam pemberian MP-ASI. Hasil pengolahan kuesioner didapatkan bahwa rata-rata tingkat pengetahun ibu menyusui terhadap ketepatan dalam pemberian MP-ASI masih dibawah 50\%. Dapat disimpulkan bahwa ibu menyusui di wilayah mitra masih memiliki tingkat pengetahuan yang rendah terhadap ketepatan pemberian MP-ASI.

Salah satu cara untuk meningkatkan pengetahuan ibu adalah dengan cara memberikan pendidikan kesehatan atau penyuluhan, yang bertujuan untuk mendorong terjadinya perubahan perilaku positif yang berhubungan dengan makanan dan gizi. Pengetahuan atau kognitif merupakan domain penting dalam terbentuknya tindakan seseorang. Menurut beberapa penelitian perilaku yang didasari dengan pengetahuan akan lebih lama dilaksanakan 
daripada perilaku yang tidak didasari dengan pengetahuan. Menurut Sukmadinata (2009), pengetahuan kesehatan memiliki pengaruh terhadap perilaku sebagai hasil jangka menengah (intermediate impact) dari pendidikan kesehatan. Perilaku kesehatan memiliki pengaruh terhadap meningkatnya indikator keesehaatan masyarakat sebagai keluaran (outcome) pendidikan kesehatan.

Berdasarkan analisis data, sehubungan dengan rendahnya tingkat pengetahuan ibu mengenai pemberian MP-ASI maka pada kegiatan penelitian dan pengabdian masyarakat ini dilakukan penyuluhan mengenai pemberian MP-ASI dalam upaya meningkatkan pengetahuan ibu tentang MP-ASI. Penyuluhan dilakukan dengan tujuan merubah perilaku ibu menyusui agar mereka tahu, mau dan mampu dalam melakukan perubahan dan perilaku kesehatan mengenai pemberian makanan pendamping ASI (MP-ASI).

\section{METODE}

Pada kegiatan pengabdian masyarakat ini, kelompok pengabdian masyarakat memberikan informasi melalui penyuluhan kesehatan mengenai pemberian MP-ASI kepada ibu menyusui yang mengikuti penyuluhan kesehatan. Kegiatan ini dilakukan secara daring melalui media zoom meeting bekerjasama dengan Praktik Bidan Bersama Citra Lestari. Tahap pertama pada pelaksanaan kegiatan ini adalah menyiapkan e-poster yang akan disebarkan kepada peserta penyuluhan serta menyusun bahan presentasi penyuluhan dalam bentuk power point presentasi. Tahap berikutnya adalah pembuatan forum zoom meeting, selanjutnya link berserta ID dan password diberikan kepada peserta penyuluhan. Penyuluhan kesehatan ini dipandu oleh moderator, selanjutnya materi dipresentasikan oleh pembicara. Pada akhir acara diberikan waktu untuk tanya jawab dan diskusi, serta berbagi pengalaman masing-masing selama pemberian MP-ASI. Setelah acara kegiatan berakhir peserta diminta untuk mengisi kuesioner posttest secara daring. Keberhasilan kegiatan dinilai dari adanya peningkatan pengetahuan ibu menyusui dalam pemberian MP-ASI. Kegiatan penyuluhan kesehatan mengenai pemberian MP-ASI ini dihadiri oleh 20 orang ibu menyusui. 


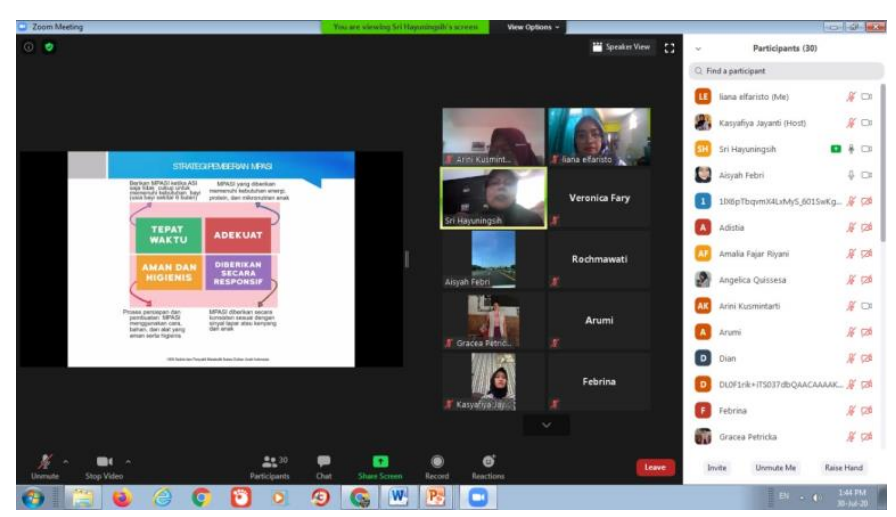

Gambar 1. Dokumentasi kegiatan penyuluhan kesehatan melalui media zoom meeting

\section{HASIL DAN PEMBAHASAN}

Telah berhasil dibuat penelitian dan pengabdian kepada masyarakat dengan program peningkatan pengetahuan masyarakat dengan cara penyuluhan kesehatan mengenai pemberian MP-ASI secara daring melalui media zoom meeting bekerjasama dengan Praktik Bidan Bersama Citra Lestari, Bojonggede, Kabupaten Bogor. Evaluasi hasil kegiatan penyuluhan kesehatan pada 20 orang ibu menyusui dilakukan berdasarkan hasil posttest yang diberikan kepada peserta setelah penyuluhan kesehatan. Berikut hasil pretest dan posttest yang dilakukan secara daring.

Tabel 1. Skor pretest dan posttest

\begin{tabular}{|c|c|c|c|c|}
\hline No & $\begin{array}{c}\text { Total skor } \\
\text { pretest }\end{array}$ & $\begin{array}{c}\text { Skor } \\
\text { pretest } \\
\text { rata-rata }\end{array}$ & $\begin{array}{c}\text { Total skor } \\
\text { posttest }\end{array}$ & $\begin{array}{c}\text { Skor } \\
\text { posttest } \\
\text { rata-rata }\end{array}$ \\
\hline 1 & 20 & \multirow{20}{*}{36} & 80 & \multirow{20}{*}{80} \\
\hline 2 & 20 & & 100 & \\
\hline 3 & 20 & & 80 & \\
\hline 4 & 40 & & 100 & \\
\hline 5 & 40 & & 100 & \\
\hline 6 & 40 & & 80 & \\
\hline 7 & 80 & & 80 & \\
\hline 8 & 40 & & 60 & \\
\hline 9 & 20 & & 100 & \\
\hline 10 & 0 & & 60 & \\
\hline 11 & 40 & & 100 & \\
\hline 12 & 80 & & 60 & \\
\hline 13 & 40 & & 60 & \\
\hline 14 & 0 & & 100 & \\
\hline 15 & 60 & & 80 & \\
\hline 16 & 40 & & 80 & \\
\hline 17 & 40 & & 80 & \\
\hline 18 & 40 & & 60 & \\
\hline 19 & 60 & & 80 & \\
\hline 20 & 0 & & 60 & \\
\hline
\end{tabular}


Evaluasi keberhasilan kegiatan penyuluhan dilihat dari hasil posttest yang diberikan secara daring melalui google form. Skor rata-rata pretest ibu menyusui adalah 36 . Nilai ratarata posttest ibu menyusui setelah mendapatkan penyuluhan adalah 80. Hasil posttest didapatkan adanya peningkatan pengetahuan ibu menyusui sebesar $122 \%$ atau terjadi peningkatan sebesar 1,2 kali lipat dari skor awal saat mengisi kuesioner pretest. Hasil evaluasi menunjukkan bahwa penyuluhan mengenai pemberian makanan pendamping ASI (MP-ASI) memberikan dampak positif berupa peningkatan pengetahuan ibu menyusui.

Kegiatan penyuluhan kesehatan ini dilakukan pada bulan Juli 2020, ditujukan untuk meningkatkan pengetahuan ibu dalam pemberian makanan pendamping ASI (MP-ASI). Pendidikan kesehatan adalah segala upaya untuk mempengaruhi orang lain, baik individu, kelompok atau masyarakat, sehingga mereka melakukan apa yang diharapkan oleh pelaku pendidikan atau promosi kesehatan (Budioro, 2012). Pendidikan kesehatan merupakan upaya atau kegiatan dalam menciptakan perilaku masyarakat yang kondusif untuk kesehatan.

Rendahnya tingkat pengetahuan ibu mengenai praktik pemberian MP-ASI disebabkan banyak faktor, salah satunya faktor sosiodemografi. Menurut penelitian yang dilakukan oleh Olatona dkk (2017) faktor sosiodemografi yang mempengaruhi pemberian MP-ASI. seperti usia, status perkawinan, tingkat pendidikan. Salah satu cara untuk meningkatkan pengetahuan ibu adalah dengan cara memberikan pendidikan kesehatan atau penyuluhan, yang bertujuan untuk mendorong terjadinya perubahan perilaku positif yang berhubungan dengan makanan dan gizi. Menurut Sukmadinata (2009), pengetahuan kesehatan memiliki pengaruh terhadap perilaku sebagai hasil jangka menengah (intermediate impact) dari pendidikan kesehatan. Perilaku kesehatan memiliki pengaruh terhadap meningkatnya indikator kesehatan masyarakat sebagai keluaran (outcome) pendidikan kesehatan.

Pegetahuan merupakan kesan yang ada di dalam pikiran manusia sebagai hasil kerja panca indra. Pengetahuan adalah hasil mengingat akan suatu hal atau kejadian (Mubarok, 2009). Penelitian yang dilakukan Kumalasari dkk (2015) menunjukkan bahwa tingkat pengetahuan ibu memperngaruhi pemberian ASI eksklusif yang sangat berkaitan dengan pemberian MP-ASI. Ibu yang memiliki pengetahuan yang baik cenderung tidak memberikan MP-ASI secara dini. Semakin baik tingkat pengetahuan ibu maka ibu akan memberikan MPASI tepat waktu. Oleh sebab itu apabila tingkat pengetahuan ibu tentang pemberian MP-ASI ditingkatkan maka ibu akan cenderung memberikan MP-ASI dengan tepat, baik dalam waktu pemberian maupun menu makanan sesuai degan gizi yang dibutuhkan. 
Berdasarkan penelitian yang dilakukan oleh Wahdini (2003), tentang Pengaruh Penyuluhan Oleh Tenaga Pelaksana Gizi dengan Metode Ceramah Disertai Media Poster dan Leaflet Terhadap Perilaku Ibu dan Pertumbuhan Balita Gizi Kurang di Kecamatan Tanjung Beringin, hasil penelitian menunjukkan bahwa penyuluhan dengan metode ceramah disertai media poster atau media leaflet dapat meningkatkan pengetahuan dan sikap ibu balita. Hal tersebut memperkuat hasil perhitungan kuesioner posttest yaitu terjadi peningkatan pengetahuan ibu menyusui tentang ketepatan dalam pemberian makanan pendamping ASI (MP-ASI) setelah diberikan penyuluhan kesehatan.

Menurut WHO (World Health Organization), MP-ASI adalah periode dimana terjadi transisi dari ASI eksklusif ke makanana keluarga meskipun pemberian ASI tetap dilanjutkan. Air Susu Ibu bermanfaat untuk tumbuh kembang bayi. WHO merekomendasikan ibu untuk menyusui bayinya secara eksklusif selama 6 bulan kelahiran. Pemberhentian pemberian ASI pada bayi akan berujung dengan diberikannnya makanan pendamping ASI (MP-ASI) (Heymann, 2013). Salah satu faktor yang menjadi penyebab penghentian menyusui dini antara lain faktor sosiodemografi, biomedis, lingkungan dan psikososial. Salah satu faktor adalah pengenalan MP-ASI secara dini (ALzaheb, 2016).

Praktek pemberian makanan pendamping ASI yang tidak tepat dapat mengakibatkan gizi buruk dan menyebabkan berbagai penyakit. Hampir setengah (45\%) kematian anak disebabkan malnutrisi. Melnutrisi menjadi faktor yang mendasari penyebab penyakit malaria, pneumonia, diare. Gizi kurang menyebabkan stunting, underweight, dan wasting. Praktik pemberian MP-ASI yang memadai dan tepat waktu tidak hanya mengatur pertumbuhan dan perkembangan fungsional dimasa anak-anak akan tetapi berdampak pada kualitas kesehatan dimasa dewasa (Metzger, 2010). Memiliki pengetahuan mengenai praktik pemberian MPASI yang baik diantara ibu dan balita akan mencegah terjadinya gizi kurang, memungkinkan anak-anak untuk mendapatkan nutrisi yang sesuai. (Aggarwal, 2008). Pemberian makanan pendamping ASI (MP-ASI) meliputi waktu dimulainya bayi boleh diperkenalkan dengan makanan pendamping, tekstur makanan pertama, menu yang diberikan di tahapan awal apakah menu tunggal atau langsung diberikan menu 4 bintang, pembagian jam makan berdasarkan usia (dibawah 1 tahun), cara agar tetap bisa menyediakan makanan yang sehat dan bergizi. Hal-hal dalam pemberian MP-ASI tersebut perlu diketahui oleh ibu. 


\section{SIMPULAN}

Kegiatan pengabdian kepada masyarakat dengan tema "Meningkatkan Pengetahuan Ibu Menyusui Melalui Penyuluhan Kesehatan Mengenai Pemberian Makanan Pendamping Asi (MP-ASI) di Wilayah Kerja Praktik Bidan Bersama Citra Lestari, Kabupaten Bogor" telah dilaksanakan sesuai dengan perencanaan tanpa kendala yang berarti. Kegiatan dilaksanakan secara daring melalui media zoom meeting. Hasil evaluasi menunjukkan adanya peningkatan tingkat pengetahuan ibu menyusui mengenai praktik pemberian makanana pendamping ASI (MP-ASI) setelah ibu menyusui mendapatkan penyuluhan. Berdasarkan analisis data tingkat pengetahuan ibu mengalami peningkatan sebanyak 1,2 kali lipat setelah ibu mendapatkan penyuluhan. Penyuluhan bertujuan agar ibu menyusui memahami dan mengerti mengenai pemberian makanan pendamping ASI (MP-ASI) sesuai standar kesehatan dan pedoman gizi. Pemberian makanan pendamping ASI (MP-ASI) yang diberikan secara tepat baik waktu dan menu makanan yang diberikan dapat meningkatkan derajat kesehatan anak serta menurunkan risiko kesakitan dan kematian bayi yang disebabkan berbagai penyakit yang umumnya menimpa anak-anak seperti diare dan radang paru, serta mengurangi angka kurang gizi (stunting).

Diharapkan kepada petugas kesehatan khususnya bidan untuk meningkatkan kualitas dan kuantitas program untuk meningkatkan pengetahuan ibu menyusui tentang ketepatan dalam pemberian MP-ASI melalui berbagai metode diantaranya menyebarkan leaflet yang berisi mengenai memberikan MP-ASI secara tepat. Memberikan penyuluhan kepada ibu menyusui danmasyarakat secara berkala. Apabila ibu menyusui sering mendapatkan informasi maka akan meningkatkan pengetahuan ibu menyusui. Perlu dilakukan rencana tindak lanjut dari kegiatan pengabdian masyarakat ini, berupa pendampingan terhadap ibu dalam merawat bayinya mulai dari pemberian ASI eksklusif, MPASI, pemberian imunisasi dan pemantauan tumbuh kembang bayi.

\section{DAFTAR PUSTAKA}

Aggarwal A, Verma S, Faridi M, Dayachand. 2008. Complementary Feeding--Reasons For Inappropriateness In Timing, Quantity And Consistency. Indian Journal of Pediatrics. 75(1):49-53.

Alzaheb, R. A. 2016. Factors Associated with the Early Introduction of Complementary Feeding in Saudi Arabia. International Journal of Environmental Research and Public Health. 13, 702. 
Arsyati \& Rahayu. 2019. Budaya Pemberian Makanan Pendamping ASI (MP-ASI) Pada Bayi Usia Kurang Dari 6 Bulan Di Desa Leuwibatu Rumpin. Hearty Jurnal Kesehatan Masyarakat. Vol.7 No. 1. 9-17.

Budioro. 2012. Pengantar Pendidikan (Penyuluhan) Kesehatan Masyarakat, Edisi Revisi, Semarang : UNDIP

Dinkes Jabar. 2018. Profil Kesehatan 2017. Germas. https://www.diskes.jabarprov.go.id/

Dinkes Kab Bogor. 2019. Buku Profil Informasi Kesehatan 2018. Germas. https://www.dinkes.bogorkab.go.id/

Heymann, J., Raub, A. \& Earle, A. 2013. Breastfeeding policy: a globally comparative analysis. Bull World Health Organ 91, 398-406, doi:10.2471/BLT.12.109363.

IDAI. 2019. Pemberian Makanan Pendamping ASI (MPASI). https://www.idai.or.id/artikel/klinik/asi/pemberian-makanan-pendamping-asi/

IDAI. 2011. Buku Ajar Nutrisi Pediatrik dan Penyakit Metabolik Jilid I. Cetakan Pertama.

Kementrian Kesehatan RI. 2019. Buku KIA Cetakan Tahun 2019. Kementrian Kesehatan Republik Indonesia.

Kumalasari. 2015. Faktor yang berhubungan dengan pemberian MP-ASI Dini. Riau: Universitas Riau.

Metzger MW, McDade TW. 2010. Breastfeeding as obesity prevention in the United States: a sibling difference model. American Journal of Human Biology.22(3):. 291-6. doi: 10.1002/ajhb.20982.

Mubarak, Iqbal. 2009. Ilmu Kesehatan Masyarakat. Teori dan Aplikasi. Jakarta: Salemba.

National Population Commission (NPC) and ICF International. 2014. Nigeria Demographic and Health Survey.

Notoadmodjo, S. 2012. Promosi Kesehatan dan Ilmu Perilaku. Rineka Cipta. Jakarta

Park, S. E. et al. 2012. Community Management Of Acute Malnutrition In The Developing World. Pediatr Gastroenterol Hepatol Nutr. 15, 210-219, doi:10.5223/pghn.2012.15.4.210.

World Health Organization. Complementary feeding. [Accessed April 20 2016]. www.who.int/elena/titles/complementary_feeding/en/last updated March 2016 